Vežbanje je lek

\title{
Exercise as a therapy
}

\author{
Sanja Mazićl,
}

${ }^{1}$ Institut za medicinsku fiziologiju "Rihard Burjan", Medicinski fakultet u Beogradu, Srbija

${ }^{2}$ Katedra za medicinu sporta, Medicinski fakultet u Beogradu, Srbija

Kontakt: sagabgyu@yahoo.com

\section{Definicija pojmova vezanih za fizičku aktivnost $i$ vežbanje}

Fizička aktivnost (engl. physical activity), prema definiciji Američkog koledža sportske medicine (The American College of Sports Medicine, ACSM) svaki je pokret tela koji je posledica mišićne kontrakcije i koji dovodi do potrošnje energije. Obuhvata širok spektar aktivnosti, od rekreativnog vežbanja i takmičarskih sportskih disciplina do fizičkih napora tokom profesionalnih aktivnosti, tokom obavljanja kućnih poslova ili dečje igre, jednom rečju, bilo koju vrstu fizičkog rada.

Fizičko vežbanje (engl. exercise), podgrupa fizičke aktivnosti, predstavlja osmišljene, definisane, repetitivne pokrete koji se izvode u cilju održanja ili unapređenja jedne ili više komponenti fizičke sposobnosti.

Fizička sposobnost, forma, fizička pripremljenost, fizički fitnes (engl. physical fitness) sposobnost je da se određena fizička aktivnost izvrši na odgovarajući i efikasan način, odnosno to je skup karakteristika koje osoba ima ili razvija, a koje su povezane sa sposobnošću za obavljanje određene fizičke aktivnosti.

Komponente fizičke sposobnosti koje su povezane sa zdravljem su: sastav tela, funkcionalna sposobnost kardiovaskularnog sistema, fleksibilnost, mišićna izdržljivost i snaga. Komponente povezane sa veštinom izvođenja određene aktivnosti su: agilnost, ravnoteža, koordinacija, sila, reakciono vreme i brzina.

Trening (engl. physical conditioning) podrazumeva redovnu, ponavljanu i strukturisanu fizičku aktivnost na nivou većem od uobičajenih aktivnosti, koja ima za cilj poboljšanje jedne ili više komponenti fizičke sposobnosti.
Sport (engl. sport) je organizovano bavljenje fizičkom aktivnošću, orijentisano prema rezultatu i regulisano pravilima. Učesnici se ili naprežu do svog fizičkog i funkcionalnog maksimuma ili izvode kompleksne veštine. Sportska aktivnost obično ima takmičarski karakter (profesionalno ili amaterski).

Savremena medicina dokazala je pozitivan uticaj fizičke aktivnosti i vežbanja na očuvanje i unapređenje zdravlja (1). Vežbanje je "polipilula" koja ne samo da leči različite bolesti već je značajno efikasnija od bilo kog leka (2). Da bi ostvarila svoj pozitivni uticaj na prevenciju i terapiju oboljenja, ona mora da bude pravilno dozirana, kao i svaki lek.

Najjednostavniji način doziranja je prema FITT formuli (3), što su početna slova engleskih reči: (Frequency, učestalost), (Intensity, intenzitet), (Time, trajanje), (Type, oblik). Treba obratiti pažnju i na tzv. VPP princip, što su skraćenice od (Volume, obim), (Pattern, princip) i (Progression, progresija).

Program vežbanja u zdravstvene svrhe ima nekoliko definisanih komponenti: kardiorespiratorne vežbe (tzv. aerobne vežbe), vežbe sa opterećenjem (tzv. "rezistens trening"), vežbe fleksibilnosti i neuromotorne vežbe (tzv. funkcionalni fitnes trening).

Za zdrave osobe mlađe od 65 godina, prema preporukama Američkog udruženja za srce (American Heart Assocoation, AHA) i Američkog koledža sportske medicine (ACSM) karakteristike programa aerobnog vežbanja koji značajno doprinosi zdravlju su (4):

- učestalost: umerena fizička aktivnost minimalno 5 puta nedeljno (po mogućstvu svakodnevno) ili intenzivna fizička aktivnost minimalno tri puta nedeljno, može i u kombinaciji; 
Tabela 1. Uporedni pregled principa doziranja leka i vežbanja

\begin{tabular}{llll}
\hline & & LEK & VEŽBANJE \\
\hline & Kontraindikacije & $\mathrm{da} / \mathrm{ne}$ & $\mathrm{da} / \mathrm{ne}$ \\
& Indikacije & $\mathrm{da} / \mathrm{ne}$ & $\mathrm{da} / \mathrm{ne}$ \\
& Doziranje & & \\
$\mathrm{F}($ frequency) & učestalost & 2 puta dnevno & $3-5$ puta nedeljno \\
$\mathrm{I}($ intensity) & doza & količina na dan & $\%$ HR max, \% HRR, \\
$\mathrm{T}($ time $)$ & trajanje & & $\% \mathrm{VO}_{2}$ max \\
$\mathrm{T}($ type $)$ & oblik & caps, tbl, i.m., ... & trajanje sesije, trajanje programa \\
\hline
\end{tabular}

$\%$ HR max - procenat maksimalne srčane frekvencije

$\%$ HRR - procenat rezerve srčane frekvencije

$\% \mathrm{VO}_{2}$ max - procenat maksimalne potrošnje kiseonika

- intenzitet: umerena do intenzivna fizička aktivnost, 55-90\% od maksimalne srčane frekvencije (HR max), odnosno 40-85\% rezerve srčane frekvencije (HRR);

- trajanje: 30-60 minuta dnevno (150 minuta nedeljno) umerene fizičke aktivnosti ili 20-60 minuta dnevno (75 minuta nedeljno) intenzivne fizičke aktivnosti, može i u kombinaciji;

- oblik: fizička aktivnost koja angažuje velike mišićne grupe, koja se odvija kontinuirano, ritmična je i aerobna po svojoj prirodi (npr. hodanje, džogiranje, vožnja bicikla, plivanje);

- obim: cilj je ukupna potrošnja od $\geq 500-1000$ MET min nedeljno (MET - metabolički ekvivalent individualne metaboličke potrebe tokom mirovanja, oko 3,5 $\mathrm{ml} \mathrm{kg}{ }^{-1}$ min $^{-1}$ ili $1 \mathrm{kcal} \mathrm{kg}^{-1}$ čas $^{-1}$, tj. $4,2 \mathrm{~kJ} \mathrm{~kg}^{-1}$ čas $^{-1}$ ), odnosno $\geq 7000$ koraka dnevno;

- obrazac: ukupno vreme vežbanja tokom dana može da se sabira, ali pojedinačna sesija ne treba da traje kraće od 10 minuta;

- progresija: treba započeti program vežbanja sa trajanjem i intenzitetom koji je prijatan za osobu, a zatim povećavati do ciljnih karakteristika koje će dovesti do zdravstveno povoljnih ili terapijskih efekata prema FITT principu.

\section{Određivanje intenziteta fizičke aktivnosti}

Intenzitet fizičke aktivnosti može da se proceni na više načina, u zavisnosti od željenog stepena preciznosti.

Procenat $\mathrm{VO}_{2} \max \left(\% \mathrm{VO}_{2} \max \right)$ najpreciznijia je metoda koja se koristi kod srčanih bolesnika, vrhunskih sportista i u naučnoistraživačke svrhe. Zahteva specifičnu aparaturu, obučen kadar i određeno vreme za izvođenje. Podrazumeva individualno određivanje vrednosti maksimalne potrošnje kiseonika maksimalnim višestepenim ergospirometrijskim testom.
Rezerva srčane frekvencije (HRR) ili Karvonenov metod pouzdan je i precizan metod doziranja, ali zahteva i poznavanje individualne jutarnje srčane frekvencije HR min (najčešće se meri tri jutra uzastopce i uzima se srednja vrednost). Smatra se da ova metoda ima visoku korelaciju sa doziranjem pomoću ostvarene vrednosti maksimalne potrošnje kiseonika $\left(\mathrm{VO}_{2} \max \right)$. Izračunava se po formuli:

$$
\mathrm{THR}=\mathrm{k} \times(\text { HR } \max -\mathrm{HR} \min )+\mathrm{HR} \min
$$

gde je THR ciljna srčana frekvencija, $k$ je koeficijent, HR max maksimalna srčana frekvencija (izračunata po formuli: 220 - godine starosti) i HR min jutarnja srčana frekvencija. Koeficijent k se izračunava ako se željeni procenat intenziteta vežbanja podeli sa 100 . Na primer, ako osoba ima 20 godina, jutarnju frekvenciju od $60 \mathrm{~min}^{-1} \mathrm{i}$ želi da vežba u režimu rada koji doprinosi očuvanju i unapređenju zdravlja (40-84\% HRR), ciljna srčana frekvencija je od $80(0.4 \times(220-20-60)+60)$ do $168(0.84 \times(220$ $-20-60)+60)$ udara u minuti.

Maksimalna srčana frekvencija (HR max) najčešće se koristi u svakodnevnoj praksi, zbog izuzetne jednostavnosti. Dobija se ako se od vrednosti 220 oduzmu gidine života osobe za koju se određuje trenažno opterećenje. $\mathrm{Na}$ primer, ako osoba ima 20 godina, HR $\max =220-20=$ $200 \mathrm{~min}^{-1}$. Ciljna srčana frekvencija, tj. zona rada koja doprinosi očuvanju i unapređenju zdravlja je $55-89 \%$ HR max, što znači da ova osoba, ako želi da ostvari svoj cilj, treba da vežba na srčanoj frekvenciji od 110 do $178 \mathrm{~min}^{-1}$ ( 200 x 0.55, odnosno 200 x 0.89). Važno je napomenuti da u praksi postoje i modifikacije ove formule (npr. za osobe ženskog pola, fizički aktivne osobe) jer ona izjednačava sve osobe za koje se izračunava, ne uzimajući u obzir nijedan individualni parametar. 
Tabela 2. Klasifikacija intenziteta rada. Preuzeto iz EACPR preporuka (5)

\begin{tabular}{|c|c|c|c|c|c|}
\hline & \multirow{2}{*}{ MET } & \multicolumn{3}{|c|}{ Relativni intenzitet (\%) } & \multirow{2}{*}{$\begin{array}{l}\text { Skala subjektivne } \\
\text { procene zamora }\end{array}$} \\
\hline & & $\mathrm{VO}_{2} \max$ & HRR & $\mathrm{HR} \max$ & \\
\hline Lagan & $2-4$ & 28-39 & $30-39$ & $45-54$ & $10-11$ \\
\hline Umeren & $4-6$ & $40-59$ & $40-59$ & $55-69$ & $12-13$ \\
\hline Težak & $6-8$ & $60-79$ & $60-84$ & $70-89$ & $14-16$ \\
\hline Vrlo težak & $8-10$ & $>80$ & $>84$ & $>89$ & $17-19$ \\
\hline Maksimalan & $>10$ & 100 & 100 & 100 & 20 \\
\hline
\end{tabular}

MET - metabolički ekvivalent (individualne metaboličke potrebe tokom mirovanja, oko $3,5 \mathrm{ml} \mathrm{kg}^{-1} \mathrm{~min}^{-1}$ ili $1 \mathrm{kcal} \mathrm{tj}_{4,2} \mathrm{~kJ} \mathrm{~kg}^{-1}$ čas ${ }^{-1}$ ), $\mathrm{VO}_{2} \mathrm{max}$ - maksimalna potrošnja kiseonika, HRR - rezerva srčane frekvencije, HR max - maksimalna srčana frekvencija, skala subjektivne procene zamora - Borgova skala

Skala subjektivnog osećaja zamora ili Borgova skala (engl. rating of perceived exertion, RPE) sastoji se od 20 numeričkih vrednosti (ocena), od kojih svaka neparna (od 7 do 19) ima verbalnu kvalifikaciju: 7 - neosetan, 9 - vrlo lagan, 11 - lagan, 13 - umereno težak, 15 - težak, 17 - vrlo težak, 19 - iscrpljujući fizički napor. Fizička aktivnost koju osoba procenjuje kao umerenu do tešku je ona koja dovodi do očuvanja i unapređenja zdravlja. Ova metoda pokazuje visoku korelaciju sa objektivnim ocenjivanjem preko ostvarene srčane frekvencije. Njeno korišćenje se ne preporučuje kod osoba sa zdravstvenim problemima.

Govor se često koristi u kliničkoj praksi, naročito u kardiologiji, kada se kardiološkim pacijentima savetuje da hodaju maksimalnom brzinom pri kojoj mogu da razgovaraju, a da se ne zadišu. Iako izuzetno jednostavan način doziranja fizičke aktivnosti, zbog uticaja velikog broja faktora nije naučno prihvaćen.

Prema preporukama Američkog koledža sportske medicine (6), vežbe sa opterećenjem tereba primenjivati (F) dva do tri dana nedeljno, pri čemu pauza između dana kada se vežba mora da bude najmanje 48 sati (I) intenzitetom od 60 do $70 \%$ repetitivnog maksimuma (RM), (T) pri čemu trajanje vežbi nije ograničeno, $(\mathrm{T})$ a preporuka je da se posebno opterećuje svaka velika grupa mišića sa 8-10 različitih vežbi, na različitim spravama i da se izvodi 8-12 ponavljanja.

Vežbe fleksibilnosti se primenjuju u cilju povećanja obima pokreta. Treba ih primenjivati (F) dva do tri dana nedeljno, (I) intenzitetom istezanja koji izaziva blag osećaj nelagodnosti, (T) svaku mišićno-tetivnu grupu treba istegnuti 2-4 puta u pojedinačnom trajanju $10-30 \mathrm{~s}$, (T) i potrebno je posebno istezati svaku od velikih mišićno-tetivnih grupa. Preporučene su i statičke (aktivne ili pasivne), dinamičke i vežbe ravnoteže, kao i proprioceptivna neuromuskularna facilitacija (PNF). Pošto su efekti istezanja najveći ako je mišić "zagrejan", pre otpočinja- nja vežbi se za povećanje fleksibilnosti preporučuju blage aerobne vežbe.

Neuromotorne vežbe se nazivaju još i funkcionalni fitnes trening. Treba ih primenjivati (F) dva do tri dana nedeljno, (I) ne postoji preporuka za intenzitet, (T) u trajanju od 20 do 30 minuta dnevno. (T) Vežbe bi trebalo da uključuju i vežbe motorike (vežbe za ravnotežu, agilnost, koordinaciju i održanje položaja tela), proprioceptivne vežbe i vežbe sa višestrukim aktivnostima (kao što su Tai Chi i joga), čiji je cilj poboljšanje fizičke funkcije i sprečavanje padova kod starijih osoba.

Smatra se da su smanjene fizička aktivnost i kretanje kod kuće, na poslu i u slobodno vreme odgovorne za 3,2 do 5,3 miliona smrti godišnje (7). To znači da je fizička neaktivnost najčešći uzrok smrti, više nego pušenje, koji je uzrok smrtnosti kod 5,1 miliona ljudi (8). Iz tog razloga nekretanje nazivaju "tihim ubicom", izazivačem sedentarnog sindroma (engl. sedentary death syndrome, SeDS) koji dovodi do obolevanja i umiranja (9). Naučno je dokazan uticaj nedovoljne fizičke aktivnosti na pojavu i progresiju kardiovaskularnih bolesti (angina pektoris, infarkt miokarda, koronarna bolest, kongestivna srčana bolest, periferna vaskularna oboljenja, hipertenzija, moždani udar), metaboličkih poremećaja (visok nivo triglicerida i holesterola u krvi, nizak nivo HDL u krvi, gojaznost, tip 2 dijabetesa), nekih maligniteta (karcinom dojke i debelog creva, tumor pankreasa i prostate), mišićno-skeletna oboljenja (osteoporoza, ukočenost zglobova, fizička slabost), psihijatrijskih oboljenja (depresija, smanjenje kognitivnih funkcija) i smanjenu imunološku otpornost organizma. Jednom rečju, nedovoljna fizička aktivnost utiče na lošiji kvalitet života i prerani mortalitet (10). Najvažnije sredstvo prevencije i najbolji lek za ove bolesti je vežbanje.

\section{Literatura}

1. Kohl HW 3rd, Craig CL, Lambert EV, Inoue S, Alkandari JR, Leetongin G, Kahlmeier S; Lancet Physical Activity Series Working Group. The pan- 
demic of physical inactivity: global action for public health. Lancet. 2012; 21;380(9838):294-305.

2. Fiuza-Luces $C$, Garatachea N, Berger NA, Lucia A. Exercise is the real polypill. Physiology (Bethesda). 2013;28(5):330-58.

3. American College of Sports Medicine (ACSM). ACSM's Guidelines for Exercise Testing and Prescription. LWW Lippincott Williams and Wilkins. 2013

4. Nelson ME, Rejeski WJ, Blair SN, Duncan PW, Judge JO, King AC et al; American College of Sports Medicine; American Heart Association. Physical activity and public health in older adults: recommendation from the American College of Sports Medicine and the American Heart Association. Circulation. 2007; 28;116(9):1094-105.

5. Vanhees L, De Sutter J, GeladaS N, Doyle F, Prescott E, Cornelissen V et al. EACPR. Importance of characteristics and modalities of physical activity and exercise in defining the benefits to cardiovascular health within the general population: recommendations from the EACPR (Part I). Eur J Prev Cardiol. 2012;19(4):670-86.

6. Garber CE, Blissmer B, Deschenes MR, Franklin BA, Lamonte MJ, Lee IM et al. American College of Sports Medicine. American College of Sports Medicine position stand. Quantity and quality of exercise for develop- ing and maintaining cardiorespiratory, musculoskeletal, and neuromotor fitness in apparently healthy adults: guidance for prescribing exercise. Med Sci Sports Exerc. 2011;43(7):1334-59.

7. Lim SS. at al. A comparative risk assessment of burden of disease and injury attributable to 67 risk factors and risk factor clusters in 21 regions, 1990-2010: a systematic analysis for the Global Burden of Disease Study 2010. Lancet. 2012; 15;380(9859):2224-60. Erratum in: Lancet. 2013 23;381(9867):628.

8. Wen CP, Wai JP, Tsai MK, Yang YC, Cheng TY, Lee MC et al. Minimum amount of physical activity for reduced mortality and extended life expectancy: a prospective cohort study. Lancet. 2011; 1;378(9798):124453.

9. Lees SJ, Booth FW. Sedentary death syndrome. Can J Appl Physiol. 2004; 29(4):447-60; discussion 444-6.

10. Vanhees L, Geladas N, Hansen D, Kouidi E, Niebauer J, Reiner Z, et al. Importance of characteristics and modalities of physical activity and exercise in the management of cardiovascular health in individuals with cardiovascular risk factors: recommendations from the EACPR (Part II). European Journal of Cardiovascular Prevention and Rehabilitation. 2012;19(5):1005-33. 